\title{
UMA UNIVERSIDADE PARA O PAMPA GAÚCHO: ESTUDO A PARTIR DE ELEMENTOS DA ESTÉTICA ORGANIZACIONAL
}

\section{RESUMO}

O objetivo geral desta pesquisa foi verificar a relação existente entre as atividades desenvolvidas pela Universidade Federal do Pampa (UNIPAMPA) e a geração de desenvolvimento para a região do Pampa Gaúcho, justificativa e objetivo principal da criação dessa universidade. Foi utilizada a teoria da estética organizacional, pois a mesma proporciona um modelo pelo qual se pode identificar os artefatos estéticos nas organizações. Os resultados encontrados indicam consenso entre os servidores da UNIPAMPA sobre seu papel com relação ao desenvolvimento da região onde está inserida e à predisposição para trabalhar com esse objetivo, que se mostra quase "enraizado" nas ideias de quem trabalha na instituição.

Palavras-chave: Universidade. Estética organizacional. Desenvolvimento regional.

\section{ABSTRACT}

This research had the intention to verify the relationship between the activities of the UNIPAMPA and the main objective of its establishment that is to generate development for the region of the Pampa Gaucho. We used the theory of organizational aesthetics, because it provides a model by which it is possible identify the aesthetic artifacts in organizations. The results indicate consensus among servers UNIPAMPA about his role in relation to the development of the region where it operates and willingness to work with this objective that is virtually "embedded" in the ideas of those working in the institution.

Keywords: University. Organizational aesthetics. Regional development.

\footnotetext{
${ }^{1}$ Doutora em Administração. Professora Adjunta da Universidade Federal do Pampa, campus de Santana do Livramento/RS. carolinafleck@unipampa.edu.br 


\section{INTRODUÇÃO}

De certa forma, coube em alguns momentos, pensar originalmente em aprendizado organizacional como uma metáfora derivada de nosso entendimento de aprendizagem individual, em um contexto onde as organizações aprendem através de seus membros individuais, transferindo seu conhecimento para as práticas organizacionais.

Não se parte do pressuposto de que essa visão tenha desaparecido ou seja considerada errônea, mas, para que se concretize, a questão crucial é a de como a aprendizagem individual é transferida à organização. Para Weick e Westley (2004), a maneira como os pesquisadores lidam com as questões sobre onde e como se insere o conhecimento nas organizações afeta a forma como os mesmos lidam com a aprendizagem. Desse modo, as partes relevantes para a aprendizagem organizacional são aquelas que constituem a memória ativa, a qual define os elementos nos quais uma organização presta atenção, como ela escolhe na hora de agir, o que ela escolhe para relembrar de sua experiência. Trata-se, assim, dos modelos mentais individuais e compartilhados. Eles podem ser explícitos ou implícitos, tácitos ou amplamente reconhecidos, mas devem ter a capacidade de afetar o modo de um indivíduo ou organização ver o mundo e ter atitudes.

Em conexão com a explicitação desses modelos mentais, formam-se características organizacionais (ritos, mitos, hábitos, etc.) que, posteriormente, vêm a ser chamadas de cultura organizacional. Toda cultura habitua aqueles que dela compartilham. A habitualização toma a forma de polaridades fundamentais que expressam oposição ou complementaridades entre extremos, os quais delineiam a percepção, a análise e a estruturação da experiência (GAGLIARDI, 2001).

No contexto das instituições e das organizações, é possível perceber a cultura como um sistema que permite a emissão e recepção de códigos que a compõem e que se preenchem de significado pelo homem que vivencia e transmite a cultura. Existe, então, um sistema de crenças e valores a partir dos quais se percebe um complexo de simbolismos, leis, padrões, divididos entre as sociedades como elementos fundamentais, que se podem chamar de sistema cultural. Esse sistema cultural parece possuir uma equivalência estrutural entre seus códigos ontológicos e seus códigos estéticos, ou seja, entre os sistemas de crenças e valores e os padrões de relação/combinação entre elementos formais (GAGLIARDI, 2001). A equivalência desses sistemas gera uma compreensão mais próxima do que realmente é a cultura organizacional.

O estudo dos elementos culturais e dos espaços organizacionais emergiu recentemente como uma das mais interessantes correntes dentro da abordagem geral por meio da quais as organizações são entendidas como culturas (GAGLIARDI, 2001). Considerando as organizações como culturas, um fator relevante tem aparecido nas pesquisas relacionadas aos elementos estéticos, que vêm ganhando espaço e demonstrando que, a partir dos artefatos organizacionais (simbolismos, leis, padrões, objetos, etc.), podem-se observar novas realidades organizacionais, com elementos mais profundos e de compreensão mais simbólica a respeito do que é a organização e sua cultura.

No estudo das organizações através de sua cultura, ou da construção desta, é possível captar processos de aprendizagem que foram fundamentais para essa forma- 
ção. Trata-se de processos que demonstram as características que fundamentam as propostas com relação ao futuro de uma determinada organização, bem como a origem do que as pessoas que estruturam essas propostas têm como princípios orientadores para as mesmas. Neste artigo, são apresentadas considerações sobre a Universidade Federal do Pampa - UNIPAMPA, no que tange a relação entre o seu objetivo de criação e as atividades que vêm sendo desenvolvidas na instituição. Esta pesquisa teve como objetivo identificar, através de uma pesquisa vinculada a elementos da estética organizacional, quais tipos de ações realizadas podem explicar a inserção de uma Universidade Federal em um contexto de economia deprimida, no qual esta tem o papel de participar do desenvolvimento desta região.

Foram entrevistadas algumas pessoas responsáveis pela construção da UNIPAMPA, buscando compreender como elas enxergam os processos adotados na universidade em prol deste objetivo, que consta no documento de sua instituição.

De forma a responder a esse objetivo, este artigo divide-se em cinco momentos. A seguir, é apresentada uma contextualização da teoria de estética organizacional. Em seguida, apresenta-se o percurso da pesquisa e o delineamento metodológico. Segue um breve relato da formação da UNIPAMPA, sob dois pontos de vista: o oficial e o que se percebe a partir de observação do cotidiano da instituição. Feito o relato, seguem as análises das entrevistas e as considerações finais do estudo.

\section{A ESTÉTICA E OS ELEMENTOS SIMBÓLICOS NAS ORGANIZAÇÕES}

O conceito de estética nas organizações tem acompanhado as pesquisas sobre a cultura das organizações como uma forma de identificar, no seu cotidiano, elementos que confiram destaque a uma compreensão do coletivo, que somente pode ser visualizada sob o ponto de vista de alguns elementos específicos, como as rotinas, ritos, mitos e elementos formais. Autores como Strati (1998; 2007; 2008), Yanow (2000) e Gherardi e Strati (1990) apresentam, em seus trabalhos, uma visão da estética nas organizações através da análise dos artefatos e das construções coletivas ali encontradas.

Existe, nas organizações, um processo contínuo de construção social, que é, ao mesmo tempo, objetivo e subjetivo. Esse processo configura-se em um tópico de estudo observável e evocativo (STRATI, 1998). É possível que se realize uma análise da construção social que os indivíduos atuantes nas organizações consolidam através da visão de que todos os elementos ali encontrados, físicos ou não, permitem. Strati (1998) ressalta que, nas organizações, podem-se visualizar planos como artefatos simbólicos. Esses planos são concebidos, então, como ensaios mentais, e, nesse caso, o planejamento é visto como autocomunicação e informação simbólica.

Considera-se a estética nas organizações como a compreensão dos símbolos, seja por sua construção, seu individualismo, seja a partir dos seus ritos, que são ações mitificadas e que acabam sendo utilizados como forma de identificação (STRATI, 1998).

A abordagem estética é considerada como fonte fundamental para compreensão do conhecimento tácito nas organizações, pois o 
Conhecimento estético é a forma de conhecimento que as pessoas adquirem através da ativação das capacidades específicas das suas faculdades perceptivo-sensoriais e juízo estético no dia a dia nas organizações. [...] Estética é aquela forma de conhecimento organizacional que é socialmente construído pessoal e coletivamente ao mesmo tempo (STRATI, 2003, p. 55).

Considerando-se que a estética permite uma análise de artefatos organizacionais, alguns pontos destacam-se sobre essa abordagem nas teorias organizacionais: 1 . a importância central da pessoa no processo de conhecimento organizacional; 2 . a corporeidade dos conhecimentos pessoais na vida organizacional; 3. o caráter socialmente construído do conhecimento estético em ambientes organizacionais; 4 . a relação entre as pessoas e formas, desde a vida cotidiana é caracterizada por um processo inesgotável de interpretação, inventando, e remodelando as formas por seus participantes (STRATI, 2003).

Para Yanow (2000), trabalhar com a cultura organizacional nos conceitos da estética permite ao pesquisador "ver" e, conceitualmente, até mesmo experimentar um aspecto social ou coletivo de aprendizagem, por causa das vinculações conceituais que transporta, em um processo metafórico, da sua nascente teórica na antropologia.

Existe uma produção de significado na organização que vai além de apenas a linha produção de um instrumento, por exemplo. Os padrões de comportamento transformam os indivíduos em uma espécie de comunidade dentro da organização.

Ainda de acordo com Yanow (2000), para analisar a aprendizagem organizacional 'culturalmente', não é preciso identificar os rituais, mitos, troféus, etc. O que é necessário para essa abordagem é um foco (centrado no significado) em qualquer trabalho que as pessoas realizem em conjunto na organização. Passa por uma perspectiva cultural interpretativa, cujo foco está no coletivo, em seus atos, nos objetos que são foco desses atos, no significado dos artefatos envolvidos na situação com o ator e no campo onde a situação é "analisada". Além disso, fundamenta-se em uma metodologia interpretativa que tem o foco em duas relações: o caráter construtivo entre um artefato e seu criador e o caráter simbólico entre o artefato e seus significados (YANOW, 2000).

O fundamental para a estética organizacional está em capturar a essência das construções simbólicas que podem ser observadas em uma organização, a partir de conexões que vão do coletivo até os artefatos e seus significados, como bem explica Yanow (2000).

Nos tópicos a seguir, iniciam-se as apresentações sobre a estruturação da pesquisa e, em seguida seus resultados, seguindo uma análise pelos propostos de identificar artefatos e seus significados nas falas dos entrevistados.

\section{A EXPANSÃO DO ENSINO SUPERIOR E AS NOVAS UNIVERSIDADES DO “INTERIOR”}

Este tópico pretende abordar especificamente o caso das instituições públicas de Ensino Superior, entendendo-se que o debate sobre a necessidade de reforma e maior atenção por parte do Governo Federal intensificou-se a partir do ano 2000.

A realidade das universidades do início dos anos 2000 era a de instituições que 
cresciam em termos de cursos de graduação e pós-graduação. Como consequência, aumentava o número de brasileiros inseridos no cenário do Ensino Superior Público. No entanto, os investimentos financeiros para que essas universidades pudessem manter-se e dar condições adequadas a cada um dos cursos em andamento não só não aumentaram como diminuíram nos últimos anos da década de 1990, conforme afirmam Lucas e Leher (2001), com base em dados de estudo do Instituto de Pesquisa Econômica Aplicada (IPEA) sobre redução das verbas de manutenção das Instituições Federais de Ensino Superior (IFEs).

Houve um período de decréscimo de investimento no Ensino Superior Público e, em consequência, um sucateamento das universidades federais. Aliado a isso, outro processo deflagrava: a estagnação das universidades em termos de abrangência nas diferentes áreas do território nacional, em especial nas regiões de interior. Os debates no meio acadêmico tornaram-se acalorados, e as críticas à falta de percepção do governo de que educação superior requer investimento e não uma "despesa a ser cortada" fizeram com que o discurso sobre a autonomia das universidades e a maior necessidade de reforma tomasse mais força, indicando que educação faz parte da formação das pessoas e que deve ser permanente e de acesso igualitário (LUCAS; LEHER, 2001; CHAUÍ, 2003). Nessa linha, Chauí (2003, p. 11) afirma que, para que a universidade pública fosse tomada por uma perspectiva melhor, deveria ser cobrado do Estado o investimento social e político necessário através da visão da educação como um direito e não um privilégio.

Por mais que houvesse debate, o que se viu até os primeiros anos da década de 2000 foi a mesma situação da década passada. A partir de 2005, a situação começou a mudar, com a elaboração de projetos educacionais que visavam aumentar o acesso da população ao ensino público. Junto a isso, houve investimento nas universidades para que as mesmas pudessem ampliar seus cursos e número de vagas. Os concursos públicos para docentes voltaram a acontecer, e os debates sobre o papel da universidade e a necessidade de reformas na estrutura atualmente utilizada voltaram ao cenário acadêmico-científico.

Além da ampliação do acesso ao ensino público, surgiu uma política para trabaIhar o desenvolvimento de regiões de economia deprimida, na qual o Governo Federal estabeleceu um programa de Desenvolvimento Regional. Esse programa prevê, entre outras medidas, a instalação de Universidades Federais com elemento dinamizador dessas economias. Foram criadas 14 novas universidades federais e mais de 100 novos campi no interior do Brasil, como a Universidade Federal do Pampa, no Rio Grande do Sul, e a Universidade Federal da Fronteira Sul, em Santa Catarina. Atualmente, todos os Estados do Brasil contam com uma IFE em seu território.

Essas instituições foram criadas para proporcionar melhor acesso ao Ensino Superior às pessoas dessas regiões e ampliar o escopo de conhecimento da região, visando ao desenvolvimento. No entanto, é importante destacar que, em sendo elemento dinamizador, não pode ser fonte de todo desenvolvimento. Será necessário, para cada uma dessas instituições, um tempo de reconhecimento do seu papel como elo de transformação para o desenvolvimento e o início do trabalho no que se refere às competências territoriais. Essas informações corroboram a proposta deste trabalho, e os dados apresentados nos capítulos seguintes poderão auxiliar na compreensão de como se dá o 
papel das universidades no processo de desenvolvimento, mais especificamente no que diz respeito ao mercado de trabalho.

\section{CONSTRUÇÃO DA PESQUISA}

Considerando-se o caráter simbólico que as pesquisas que abordam a questão da estética organizacional possuem e o objetivo deste estudo, o de identificar elementos/artefatos que demonstrem a preocupação e as ações da Fundação Universidade Federal do Pampa em prol do desenvolvimento da região do Pampa Gaúcho - propósito de sua criação, este estudo fundamentou-se em uma abordagem interpretativa, mesclando algumas técnicas de coleta de dados e análise dos mesmos.

Sendo a autora docente na instituição pesquisada, o percurso do estudo começou com algumas percepções acerca de como a consolidação da UNIPAMPA vem sendo conduzida por seus dirigentes, docentes, técnicos e discentes. A partir dessas percepções, a pesquisa direcionou-se para identificar o que Yanow (2000) chama de caráter simbólico entre o artefato e seus significados. Lembra-se que não se tratam aqui de artefato apenas objetos físicos, mas sim, as ações coletivas e seus atos e resultados e fundamentalmente os significados destes.

Esta pesquisa ocorreu entre o segundo semestre de 2009 e primeiro semestre de 2010 e envolveu diretores de campi, pró-reitores e reitoria através de entrevistas com os mesmos. Na primeira fase da pesquisa, a autora utilizou-se apenas de elementos coletados por observação participante. Já na segunda etapa, foram envolvidas as pessoas dos cargos acima mencionados através de entrevistas. No tópico a seguir, são apresentados os procedimentos metodológicos adotados.

\section{Delineamento metodológico}

Esta pesquisa segue uma abordagem qualitativa de pesquisa, utilizando como técnica de coleta de dados a observação participante, análise de documentos e Delphi. Conforme anteriormente mencionado, sendo a autora deste estudo vinculada à Instituição analisada, utilizou-se a técnica de observação participante para dar origem à base de conhecimento a ser contemplado nas entrevistas realizadas. A observação participante serviu para melhor interação com o ambiente analisado e compreensão detalhada de como ocorre a experiência de trabalhar o objetivo de criação da universidade no contexto de trabalho da autora e dos demais colegas que atuam na UNIPAMPA e dá ao pesquisador melhores meios de analisar o ambiente de pesquisa justamente pela aproximação que se tem com o mesmo. Durante a observação, foi possível identificar, em documentos e nos procedimentos rotineiros da instituição, ações relacionadas ao seu papel, por assim dizer fundamental, de gerar desenvolvimento para a região do Pampa Gaúcho, considerada atualmente uma região de economia deprimida. As informações obtidas na observação foram confrontadas com as posteriormente obtidas com as entrevistas através da técnica Delphi e dos documentos analisados.

A técnica Delphi é uma técnica para a busca de um consenso de opiniões de um grupo de especialistas a respeito de eventos futuros (WRIGHT; GIOVINAZZO, 2000). Tem 
como objetivo obter o mais confiável consenso de opinião de um grupo de especialistas. Isso é alcançado por meio de uma série intensiva de questionários entremeados com feedback controlado de opiniões (DALKEY; HELMER, 1963). No caso aqui apresentado, os especialistas selecionados foram os dirigentes da Fundação Universidade Federal do Pampa, que têm total acesso a todas as ações que vêm sendo realizadas na instituição e como a mesma tem trabalhado a inserção e a atuação na região do Pampa Gaúcho. 0 grupo selecionado constitui-se por: diretores dos dez campi da UNIPAMPA (São Borja, Itaqui, Alegrete, Uruguaiana, São Gabriel, Sant'Ana do Livramento, Dom Pedrito, Bagé, Caçapava do Sul e Jaguarão), os sete pró-reitores, a reitora e o vice-reitor. Todos foram contatados para verificar a disponibilidade de participar da pesquisa. Dentre os 19 listados, nove deram um retorno positivo para participação nas entrevistas. Destes, cinco realmente responderam e participaram das duas rodadas de entrevista necessárias para filtrar os elementos aqui apresentados.

Os dados coletados foram analisados através da técnica de análise de conteúdo clássica, sendo filtrados por tópicos que permitiam levantar novas questões, aprofundando o tema e aproximando os participantes do consenso necessário para um bom retorno da técnica de coleta utilizada. No entanto, a autora optou por apresentar os dados não em categorias, mas a partir de um quadro estruturado com os tópicos de análise da teoria da estética organizacional. Nos tópicos a seguir, são apresentados os resultados encontrados sobre os elementos/artefatos referentes à Fundação Universidade Federal do Pampa que se relacionam com seu objetivo de auxiliar no desenvolvimento da região do Pampa Gaúcho.

\section{A INSERÇÃO NA UNIPAMPA NA REGIÃO DA CAMPANHA GAÚCHA}

Neste tópico, segue um breve histórico da UNIPAMPA, retirado de fontes oficiais, como o site da instituição e do Ministério da Integração do Governo Federal do Brasil, e, em seguida, um histórico fundamentado na observação da autora na fase inicial da pesquisa.

\subsection{A formação da UNIPAMPA}

O Governo Federal, através de programa de expansão das universidades federais do Brasil, promoveu um Acordo de Cooperação Técnica financiado entre o Ministério da Educação, a Universidade Federal de Pelotas (UFPel) e a Universidade Federal de Santa Maria (UFSM), prevendo a ampliação de ações no âmbito da Educação Superior Pública na região sul do Estado do Rio Grande do Sul. A Lei 11.640, de 11 de janeiro de 2008, em seu artigo primeiro, institui a Fundação Universidade Federal do Pampa - UNIPAMPA, de natureza pública, vinculada ao Ministério da Educação, com sede e foro na cidade de Bagé, Estado do Rio Grande do Sul. Fica definido, no texto da Lei, que a UNIPAMPA terá por objetivos ministrar Ensino Superior, desenvolver pesquisa nas diversas áreas do conhecimento e promover a extensão universitária, caracterizando sua inserção regional, mediante atuação multicampi na mesorregião Sul do Rio Grande do Sul. De acordo com o Ministério da Integração, a Mesorregião da Metade Sul do Rio Grande do Sul é 
um território de aproximadamente $150.000 \mathrm{~km}^{2}$, com 104 municípios fazendo fronteira com o Uruguai e a Argentina. Atualmente, a UNIPAMPA possui 10 campi nas cidades de Alegrete, Bagé, Caçapava do Sul, Dom Pedrito, Itaqui, Jaguarão, Santana do Livramento, São Borja, São Gabriel e Uruguaiana, com mais de 30 cursos de graduação em funcionamento e mais de 3.700 alunos.

\subsection{A história que vem sendo construída}

Oficialmente, a Fundação Universidade Federal do Pampa só foi instituída no início de 2008, conforme mencionado no tópico anterior. Nos dois anos anteriores, sua história está diretamente vinculada a outras duas instituições de ensino gaúchas: a Universidade Federal de Santa Maria e a Universidade Federal de Pelotas. Foram cinco campi designados para cada uma das instituições, que tinham como dever tutelar os dois primeiros anos dessa Universidade em formação.

Assim, os primeiros grupos docentes e técnicos vieram oriundos de transferências ou de concursos dessas duas instituições e trouxeram consigo todos os ritos que as universidades de origem mantinham. Ou seja, uma nova universidade estava em formação, sob a tutela de duas instituições diferentes, com atos e objetos diferentes, e os campi ficaram divididos nessas duas óticas.

Os dois anos seguintes a sua instauração como universidade (2008 e 2009) sofreram reflexo direto dessa diversidade de formação. Essas influências, por um lado, podem apresentar benefícios, pois trazem diferentes pontos de vista e geram, para a instituição, um caráter heterogêneo. Por outro lado, geram divergências que, para uma universidade em construção, poderiam, se não prejudicar, atrasar alguns processos (como questões de carga horária disciplinar; horários entre campi; número de créditos pelo total de carga horária, entre outros processos administrativos). Além disso, nenhuma das duas universidades tutoras atuava especificamente na região do Pampa. Com isso, pode-se dizer que apenas a partir de 2008 a UNIPAMPA realmente deu início ao pensar sobre a região onde estava inserida e como poderia atuar em prol desta. Assim, precisou, em primeiro lugar, organizar-se em torno de uma estrutura única, pois, apesar de estar distribuída em dez diferentes cidades, a universidade é uma só e deve manter-se como tal. No tópico a seguir, esses elementos podem ser mais bem percebidos através das análises das entrevistas realizadas pela técnica Delphi.

\subsection{As contribuições da UNIPAMPA para o desenvolvimento da Região do Pampa}

Ser uma Universidade criada com o objetivo de atuar como agente transformador em uma região de forma a gerar desenvolvimento para a mesma não é um propósito que se possa considerar simples. Mas ser Universidade não é um propósito simples, pois o objetivo fundamental de uma instituição de ensino é a educação. Quando se trata de educação superior, exige-se mais, pois, dos formados em nível superior, esperam-se as "muitas vezes, fantásticas" soluções para os problemas de uma nação.

A Fundação Universidade Federal do Pampa faz parte do rol de novas universidades criadas pelo Governo Federal nos últimos anos. Essas universidades têm principal- 
mente os objetivos de levar educação superior pública para o maior número possível de estudantes e de abranger as áreas consideradas "descobertas" de Ensino Superior. No entanto, na UNIPAMPA, ainda existe o objetivo de ser ator responsável pelo início do processo de desenvolvimento da região onde foi inserida.Trata-se de um objetivo que, tecnicamente, pode ser considerado algo além do propósito de uma Universidade, pois pode ser visto como o pensar de uma "tábua de salvação" de uma determinada região. No entanto, pela lógica de que a Universidade, pela tríade ensino-pesquisa-extensão, pode impulsionar alguns elementos geradores de desenvolvimento.

Na primeira rodada de entrevistas desta pesquisa, os participantes foram questionados justamente sobre esse propósito, a partir de uma única pergunta, ampla, conforme segue: Como você vê a UNIPAMPA, no contexto de unidade geradora de desenvolvimento para a região do Pampa Gaúcho? Que elementos na estruturação da Universidade podem ser destacados como fundamentais para o cumprimento deste propósito?

Ao retornar a pesquisa, a maioria dos respondentes deu destaque para questões como a de a UNIPAMPA ter papel relevante no desenvolvimento da região onde está inserida, e não apenas no que diz respeito às questões econômicas. Os respondentes também pontuaram que a universidade, sozinha, não pode ser responsável pelo desenvolvimento de uma região.

Existe um consenso na instituição de que uma universidade sozinha não gera desenvolvimento, mas tem papel fundamental no propósito de buscar o desenvolvimento. Uma Universidade é, por certo, de grande potencial para a alavancagem do desenvolvimento de uma região. Mas seu potencial como "unidade geradora de desenvolvimento para a região do Pampa Gaúcho" tem óbvios/grandes limites. Não se pode ter ilusões sobre isso, porque isso mesmo seria paralisante - antidesenvolvimento (Entrevistado 2).

Apesar de ter claro que a UNIPAMPA sozinha não gera desenvolvimento, os entrevistados têm clareza sobre a importância dada à criação da instituição na região onde foi inserida. O primeiro impacto direto e imediato no desenvolvimento da região do Pampa Gaúcho e Fronteira Oeste, onde a UNIPAMPA está instalada, refere-se às pessoas envolvidas no contexto da UNIVERSIDADE e devidamente inseridas nas respectivas comunidades (Entrevistado 9).

Como esperado, numa primeira fase de instalação, que eu arriscaria dizer que vai durar os primeiros 10 anos da universidade, o impacto da universidade se dá de modo bastante visível e provocando o que chamamos crescimento econômico. Existe um movimento de agregação de pessoas vindas de diversos lugares que vão integrar o cenário regional e nele vão colocar recursos na forma de aluguéis, alimentação, livros, consumo em geral. A própria UNIPAMPA tende a formar relações comerciais com empresas e pessoas locais, contribuindo para este movimento econômico, seja direta, ou indiretamente. Novas possibilidades de prestação de serviços e de fornecimento de produtos vão se instalando, a fim de atender à demanda da instituição, bem como tende a ocorrer a qualificação e especialização de empresas já existentes. Todo este cenário já é visível nas cidades onde a UNIPAMPA está instalada (Entrevistado 6).

Nesse contexto, foram evidenciados elementos bem pontuais, como: 1) a possibilidade de Ensino Superior Público, gratuito e de qualidade a uma parcela da população que não teria condições de deslocamento e permanência nos centros onde existe IFES no 
Estado; 2) diferentes opções de empregos dos que eram oferecidos até então; 3) uma população de servidores e discentes para residir e consumir nas cidades do entorno da Universidade; 4) uma nova filosofia e visão de mundo principalmente para os jovens da região (Entrevistado 8).

A partir dos elementos encontrados nas falas reproduzidas, vê-se formar uma cultura em torno do objetivo fundamental da instituição. Surpreendentemente, já se encontrou consenso na primeira rodada de entrevistas, especialmente sobre o fato da universidade não ser vista como o pilar de sustentação de um processo de desenvolvimento para a região do Pampa Gaúcho. Percebem-se, entre os entrevistados, objetivos comuns de atuar em uma Universidade em construção e com desafios a serem vencidos. De docentes a técnicos administrativos, os objetivos do trabalho voltam-se para atender às proposições apresentadas no plano institucional da UNIPAMPA. Os artefatos institucionais constituem-se nos planos estruturados e executado em consonância com o objetivo de criação da universidade e com as atividades a serem desempenhadas pelos indivíduos envolvidos.

Os entrevistados deixam claro como percebem o papel da UNIPAMPA no desenvolvimento da região do Pampa Gaúcho, no entanto faltou clareza no que diz respeito a como isso tem sido trabalhado no contexto diário da instituição. Também não se deixou claro o modo como são as ações efetivas que dão vazão ao que é estruturado nos planos institucionais. Para compreender melhor esses elementos, foi necessária uma segunda rodada de entrevistas, na qual foi perguntado aos entrevistados: Está a comunidade ciente deste papel de um "eixo" de transformação e não de unidade transformadora? o que é preciso fazer para que o desenvolvimento seja alcançado a partir de ações da universidade? As políticas institucionais da universidade dão conta deste propósito ou é preciso mais?

Nessa rodada, aparecem nas entrevistas sinais de compreensão da necessidade de mais tempo para que os elementos que podem gerar desenvolvimento se concretizem e uma ênfase no fato de que as ações já tomadas pela instituição começam a demonstrar sinais de relação positiva com o objetivo de criação da instituição. Nos trechos a seguir, percebe-se de forma mais clara esse resultado.

A impressão que tenho é que a comunidade espera uma ação salvadora de qualquer ator que possa ter alguma expressão no processo de desenvolvimento regional. Ou seja, a comunidade espera que a universidade seja uma unidade transformadora. [...] é preciso avançar-se na proposta de projetos de ensino, pesquisa e extensão que tenham impacto direto na comunidade e em empresas ou organismos locais ou regionais. Precisamos fazer com que a 'expertise' acumulada pela universidade ganhe espaço como elemento de transformação na prática, mesmo que seja por ações pontuais. [...] Todas as políticas institucionais estão sendo estabelecidas sobre a missão da universidade. Isso faz com que sejam coerentes com este aspecto de sua existência. No entanto, a universidade precisa de tempo para exercer sua missão, muito de seu impacto será percebido apenas no médio ou no longo prazo (Entrevistado 6).

Sempre é necessário ampliar os investimentos para o desenvolvimento, a comunidade externa espera que sejamos alavanca de desenvolvimento, e acredito que a Unipampa tem políticas institucionais que dão conta deste propósito, por exemplo, as inú- 
meras bolsas aos discentes (PBDA, PBP, PIBIC, etc. ), os cursos de extensão e agora mais recentemente com o apoio a rede pública de Ensino Básica (Plataforma Freire, PIBID), são ações indutoras de desenvolvimento (Entrevistado 8).

Essas falas reproduzem alguns dos programas utilizados pela Universidade para despertar maior envolvimento dos alunos com pesquisa e extensão e, concomitantemente, gerar benefícios como auxílio financeiro. É simples perceber que os artefatos fundamentais da cultura da instituição de Ensino Superior pesquisada estão em torno do ensino, pesquisa e extensão. Construíram-se, em torno da tríade, as estratégias e os planos que deverão atender ao objetivo de ser uma instituição para impulsionar o desenvolvimento da região do Pampa Gaúcho.

A partir dos dados coletados com os entrevistados, comparando com os aspectos apontados na literatura, é possível realizar um esquema comparativo que aponta para os seguintes artefatos institucionais constituintes do debate em torno do objetivo da instituição e as ações que devem ser efetivadas para o mesmo (Figura 1).

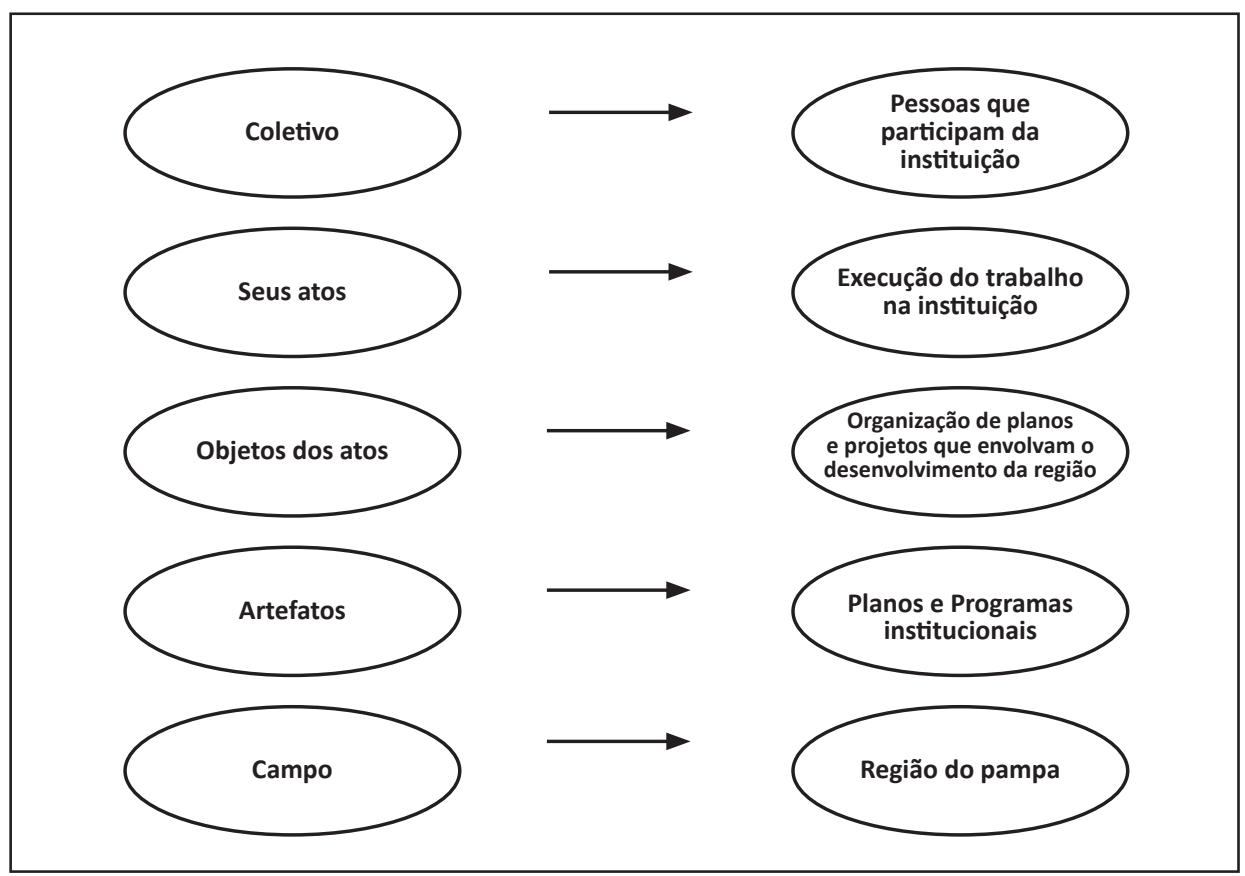

Figura 1: Esquema comparativo entre os elementos apresentados na teoria da estética organizacional e os elementos encontrados no resultado da pesquisa Fonte: Elaborado pela autora.

Pela perspectiva cultural interpretativa, é possível identificar claramente, entre os elementos retirados das entrevistas, os pontos destacados por Yanow (2000). Existe um encadeamento entre todos esses elementos, reforçando os argumentos da teoria de estética organizacional, segundo a qual artefatos e os indivíduos que os constituem não se dissociam. 
Os resultados das duas rodadas de entrevistas foram satisfatórios especialmente pelos níveis de consenso encontrados entre os respondentes. Mesmo sendo necessária a segunda rodada para melhor compreender quais os elementos fundamentais para que a UNIPAMPA venha a cumprir o objetivo de impulsionar o desenvolvimento regional, foram duas rodadas em que os entrevistados apontaram para elementos muito semeIhantes. Isso permitiu a construção de um esquema comparativo com a teoria e a tabulação das análises das entrevistas em um quadro síntese, como pode ser visualizado no Quadro 1.

\begin{tabular}{|l|c|l|l|}
\hline \multicolumn{1}{|c|}{ Elementos } & $\begin{array}{c}\text { Rodada em que } \\
\text { foram identificados }\end{array}$ & \multicolumn{1}{|c|}{ Exemplo } & \multicolumn{1}{|c|}{$\begin{array}{c}\text { Nível de } \\
\text { consenso }\end{array}$} \\
\hline $\begin{array}{l}\text { Potencial para gerar } \\
\text { desenvolvimento }\end{array}$ & 1 & $\begin{array}{l}\text { Falas dos entrevistados } \\
2,6,8 \text { e } 9\end{array}$ & Total \\
\hline $\begin{array}{l}\text { Não é o ponto central } \\
\text { gerador de desenvolvimento }\end{array}$ & 1 & $\begin{array}{l}\text { Falas dos entrevistados } \\
2,6,8 \text { e 9 }\end{array}$ & Total \\
\hline $\begin{array}{l}\text { Deve priorizar no ensino, } \\
\text { pesquisa e extensão } \\
\text { suas atividades }\end{array}$ & 2 & $\begin{array}{l}\text { Falas dos entrevistados } \\
6 \text { e 8 }\end{array}$ & Total \\
\hline Programas de bolsas & 2 & Fala do entrevistado 8 & $\begin{array}{l}\text { Maioria dos } \\
\text { respondentes }\end{array}$ \\
\hline Programas interinstitucionais & 2 & Fala do entrevistado 8 & $\begin{array}{l}\text { Maioria dos } \\
\text { respondentes }\end{array}$ \\
\hline $\begin{array}{l}\text { Diálogo com autoridades } \\
\text { locais e comunidade }\end{array}$ & 1 & Fala do entrevistado 2 & Consenso \\
\hline $\begin{array}{l}\text { Interação com empresas e } \\
\text { órgãos públicos }\end{array}$ & 1 & Fala do entrevistado 6 & Consenso \\
\hline
\end{tabular}

Quadro 1: Resumo com os principais resultados da pesquisa Fonte: Elaborado pela autora.

Consideram-se esses resultados satisfatórios ao objetivo proposto. No entanto, pretende-se ainda uma análise dos documentos consolidados como planos institucionais e estatuto da instituição como comparativo com os dados aqui coletados. Com essa ampliação do escopo de análise para a pesquisa, pode ser possível acrescentar elementos ou, pelo menos, melhor explicar como os artefatos encontrados apresentaram níveis altos de consenso nas entrevistas.

\section{CONSIDERAÇÕES FINAIS}

O atual contexto brasileiro da educação superior proporcionou, nos últimos anos, uma expansão das universidades federais em diversas regiões do país. Entre elas, está a região do Pampa no Rio Grande do Sul, que teve estruturada e iniciada em 2006 a Fundação Universidade Federal do Pampa. Trata-se de uma instituição multicampi que atua em dez cidades no Estado Gaúcho, com mais de 40 cursos de graduação.

O projeto da UNIPAMPA visava e visa ao desenvolvimento de uma região de economia deprimida através da geração de conhecimento para a população que vive no 
Pampa Gaúcho, mas também atraindo pessoas de outras regiões do Rio Grande do Sul e do Brasil. Esse fato vem se concretizando a cada início de ano, com as novas turmas e com a criação de novos cursos. No entanto, fica claro nesta pesquisa, e também quando se observa o desenvolvimento da universidade, que uma instituição de Ensino Superior não pode ser responsabilizada por gerar desenvolvimento para uma região que há anos enfrenta problemas de desenvolvimento. Pode, sim, ser impulsionadora em alguns aspectos e deve participar como agente de transformação, mas não sozinha. As universidades devem ser um elo de uma corrente que envolve órgãos como governo municipal, estadual e federal, as empresas da região e as externas que venham a investir no local, entre outras.

Nesta pesquisa, o objetivo fundamental era o de utilizar a teoria da estética organizacional como forma de identificar elementos/artefatos que pudessem demonstrar a relação que vem se estabelecendo entre os indivíduos atuantes na UNIPAMPA e o objetivo da sua criação, de que seria uma universidade para gerar desenvolvimento regional. No final da análise, estruturou-se um quadro-resumo que permite visualizar melhor os resultados encontrados, no qual se define claramente que as pessoas que atuam na instituição têm configurado, no seu dia a dia, o papel desenvolvimentista da universidade. Também está clara a responsabilidade que envolve trabalhar com o propósito de desenvolver uma região, observando que, sozinha, a UNIPAMPA não tem esse poder. Resgatando os aspectos da teoria, vê-se claramente o coletivo, com seus atos e objetos, que se definem por artefatos dessa estrutura organizacional, estruturando o campo das interações sobre o propósito do desenvolvimento regional. Como conclusão específica da inserção da estética organizacional em estudos para melhor compreensão das universidades, cabe destacar a utilidade da teoria, que transborda os limites de uma compreensão simples para contribuir com análises mais profundas e detalhadas das organizações.

Em termos de UNIPAMPA, os resultados encontrados apontam também para elementos como planos e projetos institucionais sendo construídos em torno da necessidade de pensar o que a região precisa e como se pode contribuir. Esses planos são utilizados pelos servidores no momento de organizar suas questões de trabalho, especialmente com os discentes. Conclui-se que, em um encadeamento lógico de ações, a universidade tem tentado seguir seu papel desenvolvimentista dentro das possibilidades de seu trabalho.

Cabe destacar também a utilização da teoria da estética organizacional como fundamentação para a análise e a relação com a técnica Delphi para coleta e análise dos dados. As teorias de Aprendizagem Organizacional e, neste caso, a estética têm consolidado pesquisas de abordagem qualitativa e com maior profundidade nas análises do material encontrado. No caso desta pesquisa, optou-se por coletar os dados através da técnica Delphi, porque o que se esperava eram respostas que pudessem demonstrar elementos comuns entre as falas dos entrevistados. Como o objetivo da técnica é encontrar consenso nas opiniões sobre um determinado assunto, parecia-nos a mais adequada e, juntamente com elementos vindos de documentos e observação, foi possível contemplar o objetivo da pesquisa.

Após a coleta e a análise dos dados, ficou clara a possibilidade de relacionar a técnica com as pesquisas em estética e cultura organizacional. Consideram-se os resul- 
tados obtidos positivos tanto no sentido do objetivo principal, quanto no que se refere à relação entre a metodologia e a teoria. Acredita-se que o estudo apresenta inovação no sentido de ampliar o escopo de análise com a teoria estética e também pela aproximação da mesma com técnicas de pesquisa já consolidadas. A utilização do modelo teórico de Strati foi conveniente para a pesquisa e sugere-se a utilização em com outros objetos e objetivos em pesquisas futuras.

\section{REFERÊNCIAS}

CHAUÍ, M. A universidade pública sob nova perspectiva. Revista Brasileira de Educação. n. 24 set./dez., 2003.

DALKEY, N.; HELMER, O. An Experimental Application of the Delphi Method to the Use of Experts. Management Science, v. 9, n. 3, , p. 458-467, abr. 1963.

GAGLIARDI, Pasquale. Explorando o lado estético da vida organizacional. In: CLEGG, Stewart; HARDY, Cynthia; NORD, Walter R. (Orgs.) Handbook de Estudos Organizacionais. v. 2. São Paulo: Atlas, 2001. p. 127-149

GHERARDI, S.; STRATI, A. The 'Texture' of Organizing In: An Italian University Department. Journal of Management Studies 27, 6 nov. 1990.

LUCAS, L. C. G.; LEHER, R. Aonde vai a educação pública brasileira? Educação e Sociedade n. 77, 2001.

STRATI, A. Knowing in Practice: aesthetic understanding and Tacit Knowledge. In: NICOLINI, Davide; GHERARDI, S.; YANOW, D. (Eds.). Knowing in Organizations: A Practice-Based Approach. Cap. 3. New York: M. E. Sharpe, 2003. p. 53-75.

STRATI, A. A esthetics in the Study of Organizational Life. In: BARRY, D.; HANSEN, H. (Eds.) The SAGE Handbook of New Approaches in Management and Organization. London: Sage, 2008. p. 229-238.

. Organização e Estética. Rio de Janeiro: FGV, 2007.

Organizational symbolism as a social construction: a perspective from the sociology of knowledge. Human Relations, n. 11, p. 1379-1402, 1998.

YANOW, D. Seeing Organizational Learning: A 'Cultural' View. Organization, May; v. 7, n. 2, p. 247-268, 2000.

WEICK, Karl; WESTLEY, Francis. Aprendizagem Organizacional: confirmando um oxímoro. In: CLEGG, Stewart R.; HARDY, Cynthia; NORD, Walter R. (Orgs.). Handbook de estudos organizacionais. v. 3. São Paulo: Atlas, 2004. p. 361-388.

WRIGHT, James T. C.; GIOVINAZZO, Renata A. Delphi - uma Ferramenta de Apoio ao Planejamento Prospectivo. Caderno de Pesquisas em Administração. v. 1, n. 12, 2 trimestre/2000. 